\title{
Evaluation of metrology technologies for free form surfaces
}

\author{
K. Arámbula ${ }^{1}$, H.R. Siller ${ }^{1, \star}$, L. De Chiffre ${ }^{2}$, C.A. Rodríguez ${ }^{1}$, and A. Cantatore ${ }^{2}$ \\ 1 Centro de Innovación en Diseño y Tecnología, Tecnológico de Monterrey, Av. Eugenio Garza Sada \#2501, 64849 Monterrey, \\ Mexico \\ 2 Department of Mechanical Engineering, Technical University of Denmark, 2800 Kgs. Lyngby, Denmark
}

Received: 21 July 2011 / Accepted: 24 March 2012

\begin{abstract}
This research work describes a novel approach for comparing different technologies for free form surface metrology: computerized tomography (CT), photogrammetry and coordinate measuring machines (CMM). The comparison has the aim of providing relevant information for the selection of metrology equipment when measuring free form components. Results demonstrate that there is the imperative need to assess the uncertainty and reproducibility of CT and photogrammetry measurements by applying some calibration procedures taking into account some recommendations for work piece alignment. This article also deals with costs issues, required standards, and necessary additional information when selecting inspection equipment.
\end{abstract}

Keywords: Freeform; metrology; computed tomography; CMM; photogrammetry

\section{Introduction}

In the last years, safety and quality demands at industry have been constantly increasing, pushing companies to be significantly strict at matters referred to tolerance of critical dimensions, failure detection and calibration of equipment. In the aim to satisfy these demands, this article makes a quantitative comparison of three different inspection technologies; computed tomography, photogrammetric technology, with the CMM measurements as reference.

Nowadays a particular interest has been scoped in curved surfaces either for functional or aesthetical reasons. These components are important in fields like aerospace, automotive, medical devices, and others.

For functional components, having geometrical deviations in manufacturing may cause waste of energy or even failures in the performance of the entire system. Design, engineering and testing of parts having functional surfaces are important activities to assure good performance [1].

In order to deliver a component within the tolerances, some innovations like machine tool touch probes [2] have permitted to measure the work piece during the production process reducing the machining and alignment time $[3,4]$.

Nevertheless, in order to have traceability according to the standards like the 15530-3 [5], Coordinate Measuring Machines (CMMs) need to be used for inspection.

In [6] it is given a qualitative table comparing different inspection technologies describing the facility to measure depending on the type of material and surface, traceability, shape complexity and the size of the part.

^ Correspondence: hector.siller@itesm.mx
The following study pretends to be a quantitative complement to direct in numbers what would be the desired measurement technology matching the cost, reproducibility, and uncertainty requirements.

The paper is organized as follows: Section 2 presents the steps to select the appropriate technology starting from analyzing the work piece at first, and getting information regarding the available technologies. In Section 3 will be described some available measurement systems in which CMM, CT, and photogrammetry were analyzed from its advantages and disadvantages especially when measuring sculptured surfaces.

The final section corresponding to the technologies comparison states some of the complications someone can encounter measuring a free form and some ways to manage uncertainty when comparing with reference measurements like CMM measurements as in the present case study. Also in Section 4, will be complemented information from [6] (the main reference article) and a decision matrix is presented in order to recommend the more suitable equipment for a specific size.

\section{Inspection technology selection}

Before the acquisition of metrological equipment there are several aspects to take into account. These can be divided as follows:

(1) characterization of the work piece to measure and understanding the equipment specifications;

(2) basic knowledge of the available measurement systems; 


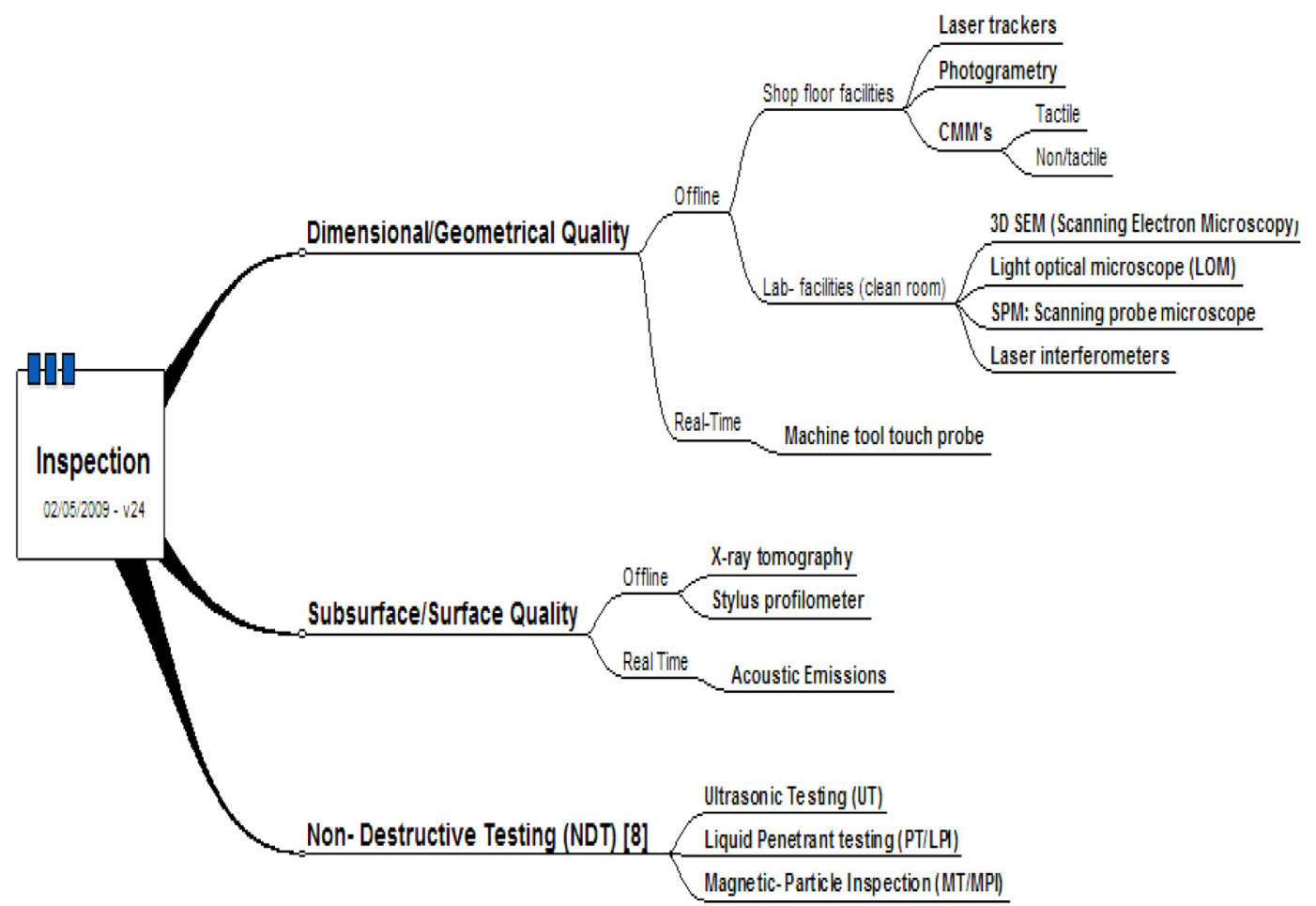

Fig. 1. (Color online) Inspection technologies classification.

(3) technologies comparison enclosing the requirements of each of the equipments.

\subsection{Sample characterization and equipment specifications}

Regarding the sample characterization aspects, the shape and the size are the initial factors to consider. In the aerospace field, the shape represents for certain inspection technologies a problem. For example; with the tactile technologies the styli can slip and break when measuring a steep curvature.

Shapes can be divided in two categories; prismatic and free form surfaces. The prismatic are geometrical parts comprising of rectangular angle's or regular pattern curves. The other types of shape, the free forms, are the skin of a 3D geometric element which does not have rigid radial dimensions. Usually they are made of splines, complex functions and its base is a gridline mesh.

Towards the size; large pieces require bigger machinery and also imply a sacrifice in accuracy. Preparation time is affected as well.

Other important aspects to consider before purchasing machinery are the equipment specifications like monitoring type and required resolution. The monitoring type refers to have real time or offline inspection. Real time, as its name implies, are the measurements carried out during the manufacturing process while offline are the measurements performed when the sample has already been manufactured and dimensions need to be inspected.

Regarding the resolution topic, this depends of the tolerance the designer desires to have on the equipment. It is necessary to contemplate as well the uncertainty of a measuring instrument, and the so called golden rule, which states a measuring instrument involved in manufacturing process inspection should have a measurement uncertainty of $10-20 \%$ of the tolerance range $U=$ Tolerance $\times$ $(0.1 \ldots 0.2)$ [7]. This rule related to the instrument or equipment alone has been replaced by the more general ISO 14253 rule relating to the measuring process. Nevertheless, the golden rule still used as a fast indicator to determinate the uncertainty of the inspection machinery.

\section{Measurement systems}

Once the sample to measure has been catalogued, it is necessary to analyze the basic characteristics, advantages and disadvantages of each of the technologies to compare.

Measurement systems can be classified in many ways; they can be divided according to applications they are made for, monitoring type, facilities, or kind of contact with the sample (see Fig. 1).

The first of these classifications refers to the function of the instrument; which can be to inspect the subsurface or surface quality, verify dimensional and geometrical values, or simple just to perform non-destructive testing (NDT).

The second division is based in "real-time" or "offline" measurements where real time refers to measurements carried out during the manufacturing process while offline are the measurements performed when the sample has already been manufactured and dimensions need to be inspected.

The last classification of the diagram mentions a subdivision in function on the facilities required for the equipment. This basically refers if the instrument is sensitive to 
Table 1. Quantitative evaluation of investigated measuring techniques on a $220 \mathrm{~mm}$ long meso scale sample.

\begin{tabular}{|c|c|c|c|c|}
\hline \multicolumn{2}{|c|}{ Technology } & X-ray tomography & Photogrammetry & Tactile CMM \\
\hline \multicolumn{2}{|c|}{ Maintenance Cost } & $8500-17000$ USD & $8500-10000$ USD & 6500 USD \\
\hline \multicolumn{2}{|c|}{ Maint. frequency } & 4 to 5 months & 4 to 5 months & 12 to 24 months \\
\hline \multicolumn{2}{|c|}{ Service cost $[\mathrm{USD}] / \mathrm{h}$} & 340 & 390 & 250 \\
\hline \multicolumn{2}{|c|}{ Traceability } & VDE/VDI 2630 & VDI/VDE 2634 & ISO15530-3 \\
\hline \multirow{2}{*}{ Uncertainty } & $\begin{array}{c}\text { Technical } \\
\text { specificatians }\end{array}$ & $4-20 \mu \mathrm{m}$ & $4-20 \mu \mathrm{m}$ & $\begin{array}{c}2-3 \mu \mathrm{m} \text { (high accuracy) } \\
4-8 \mu \mathrm{m} \text { (med. accuracy) [12] }\end{array}$ \\
\hline & $\begin{array}{c}\text { Original } \\
\text { experimental data }\end{array}$ & $\begin{array}{cc}\text { MPE } & \text { Total U } \\
11 \mu \mathrm{m} & 13 \mu \mathrm{m}\end{array}$ & $\begin{array}{l}\text { Total U } \\
13 \mu \mathrm{m}\end{array}$ & $\begin{array}{c}\text { Total U } \\
5 \mu \mathrm{m}\end{array}$ \\
\hline & Reproducibility & $21 \mu \mathrm{m}$ & $18 \mu \mathrm{m}$ & $5 \mu \mathrm{m}$ \\
\hline \multicolumn{2}{|c|}{ Recommendations } & $\begin{array}{l}\text { Important to locate } \\
\text { coordinate system } \\
\text { Alignment according } \\
\text { to reference artifact }\end{array}$ & $\begin{array}{l}\text { Important to locate } \\
\text { coordinate system } \\
\text { Alignment according } \\
\text { o reference artifact }\end{array}$ & $\begin{array}{l}\text { Important to define } \\
\text { alignment and number of } \\
\text { points to align }\end{array}$ \\
\hline
\end{tabular}

vibrations or temperature. In case the apparatus is sensible to such matters then a clean room or laboratory is required; if not, a shop floor would be an appropriate place to assure a good performance and measurements accuracy (see Fig. 1).

Another common way to classify the metrological equipment is by the type of contact with the work piece.

Contact technologies or Coordinate Measuring Systems (CMS); include all instruments capable of measuring points in space based in the $X Y Z$ Cartesian coordinate system. Examples of contact technologies are CMM, FARO arm touch probe, machine tool touché probe, etc.

Many of non-contact technologies are based on triangulation techniques, which basically rely on detecting reflected light from an external source. This source can be a laser, light beam, or any kind of radiation.

For devices using a light beam for inspection, one of the biggest disadvantages of these technologies is commonly referred to the sensivity to translucent/reflective materials which require preparation in order to be inspected. Such preparation requires spraying parts affecting accuracy with an approximate of $3-5 \mu \mathrm{m}$ (spray particles $0.2 \mu \mathrm{m})$. For the ones that do not use laser, like photogrammetry, but use X-rays, this is not a problem.

Another common disadvantage of non-contact techniques in general, are the uncertainty contributors often not well known or documented. There is no traceability at all with optical methods [9] and for such reason tactile technologies still being the first option to inspect.

Since the non-contact technologies receive as an output a point cloud image rather than coordinates, the factors that describe the quality of such image depend on 4 aspects [10]:

- point density;

- completeness;

- noise;

- accuracy.
Some examples of non-contact equipment are laser trackers, computed tomography, laser scanners, photogrammetry, etc.

For the purpose of the present study only CMM's, photogrammetry and CT are considered.

\subsection{Coordinate Measuring Machine (CMM)}

Coordinate Measuring Machines (CMMs) are the most important general purpose instruments for inspection in the industry.

When the geometrical accuracy of freeform surfaces is critical for the functional performance, or for the appearance of a product, the inspection process is typically conducted on CMMs [6].

They are able to measure thousands of points, even on complex surfaces (200 points/s at speeds as high as $150 \mathrm{~mm} / \mathrm{s}$ ) [11] and are today typically provided with numeric control and scanning probes, both contact and noncontact; automatic measurements of thousands of points are easily performed, even on complex surfaces.

As it is known in basic metrology, there is a minimum recommended of points to represent diameters, angles, etc. but yet there is not a stated minimum points suggestion for point clouds in sculptured surfaces. This also increases the programming/inspection time which can be divided in setting, calibration, and measuring time. The setting time on the CMM depends on the personnel's experience to align, and manage the freeform sample. For a meso-scale sample with an area of $220 \mathrm{~mm}$ length and 85 width the estimated setting time is around $120 \mathrm{~min}$, for calibration $60 \mathrm{~min}$, and inspecting the work piece both sides, $40 \mathrm{~min}$. Such time employed in the measurements affects directly the final cost of service, $250 \mathrm{USD} / \mathrm{h}$ (see Tab. 1) making it a disadvantage despite the trade-off between time and the accuracy due the amount of points to inspect. 
Table 2. Costs and instruments MPE per measuring sample length.

\begin{tabular}{|c|c|c|c|c|c|}
\hline$\stackrel{\sim}{\sim}$ & $\begin{array}{l}\text { Name and } \\
\text { subsystem }\end{array}$ & $\begin{array}{c}\text { Aprox. } \\
\text { measuring } \\
\text { length }\end{array}$ & $\begin{array}{l}\text { Cmm cost } \\
\text { and MPE }\end{array}$ & $\begin{array}{l}\text { Photogrammetry } \\
\text { cost and MPE }\end{array}$ & $\begin{array}{c}\text { Computed } \\
\text { Tomography } \\
\text { cost and MPE }\end{array}$ \\
\hline 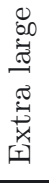 & $\begin{array}{c}\text { Fiixed and } \\
\text { moveable wing } \\
\text { structures }\end{array}$ & $10000 \mathrm{~mm}$ & $\begin{array}{c}750000 \text { USD } \\
100 \mu \mathrm{m} \\
\text { (volumetric) [13] }\end{array}$ & $\begin{array}{l}230000 \text { USD } \\
400 \mu \mathrm{m}[12]\end{array}$ & $\mathrm{N} / \mathrm{A}$ \\
\hline 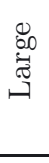 & Skin pannel section & $1000 \mathrm{~mm}$ & $\begin{array}{c}680000 \text { USD } \\
90 \mu \mathrm{m} \\
\text { (volumetric) [14] }\end{array}$ & $\begin{array}{l}230000 \text { USD } \\
100 \mu \mathrm{m}[12] \\
\end{array}$ & $\mathrm{N} / \mathrm{A}$ \\
\hline $\begin{array}{l}0 \\
\text { त्र } \\
\text { D } \\
0 \\
0\end{array}$ & $\begin{array}{l}\text { Carbon heatpack } \\
\text { (aircraft brakes) }\end{array}$ & $750 \mathrm{~mm}$ & 365000 USD & 200000 USD & $\begin{array}{l}720000 \text { USD } \\
20 \mu \mathrm{m}[17]\end{array}$ \\
\hline$\sum$ & Turbine blades & $500 \mathrm{~mm}$ & $\begin{array}{l}98055 \text { USD } \\
4 \mu \mathrm{m}[16]\end{array}$ & $\begin{array}{l}155000 \mathrm{USD} \\
20 \mu \mathrm{m}[12] \\
\end{array}$ & $\begin{array}{l}720000 \text { USD } \\
10 \mu \mathrm{m}[17]\end{array}$ \\
\hline 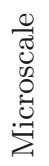 & $\begin{array}{c}\text { MK66 rocket } \\
\text { nozzlz }\end{array}$ & $70 \mathrm{~mm}$ & $\begin{array}{l}98055 \text { USD } \\
3 \mu \mathrm{m}[16]\end{array}$ & $\begin{array}{l}160000 \text { USD } \\
10 \mu \mathrm{m}[12]\end{array}$ & $\begin{array}{c}240000 \text { USD } \\
5 \mu \mathrm{m}[18]\end{array}$ \\
\hline
\end{tabular}

Another disadvantage is the lack of portability of this technology. Nevertheless, CMM's have imperative advantages in other aspects:

- relative low maintenance cost, approximately 6500 USD, and frequency, 12-24 months (see Tab. 1);

- comparative low equipment cost depending on the size of the machine (see Tab. 2);

- low MPE independently the size of the machine (see Tab. 2);

- they are flexible systems allowing measurement of points in space with high accuracy [11];

- CMMs have traceability towards the "meter" unit (IEC 15530) [5].

According to the technical specifications for the uncertainty assessment required by ISO 14253-1 and the developed standards under the 15530 (ISO Technical Committee 213), the use of calibrated work pieces (2004) is recommended in order to make measurements traceable.

In the field of sculptured surfaces metrology, previous evidence of a free form gauge can be found in [6], or in the free form assembly made in [8]. The complexity relies in having a calibrated gauge within the stipulated resemblance with the work piece required for the IEC 15530-3 standard.

The alignment of complex surfaces is another quite difficult task in the CMM. Using the normal 3-2-1 rule might not be possible due to the absence of plane surfaces in a free form. This leads to two other methods.
- Spheres alignment;
- CAD alignment.

Spheres alignment consists in referencing to a datum. Each center of the sphere represents a datum in the profile. This method is the most accurate but it takes time in comparison to the CAD alignment. Using this method can also be confusing due the different possibilities to align. Some softwares include specific functions like best fitting alignment, RPS alignment, among others. Nevertheless it is important to preserve consistency with the alignment made in the gage, and for the CMM measurement after trespassing the results with the CAD comparison maintaining the same point locations for stitching with the CAD.

\subsection{X-ray tomography (CT)}

Computed tomography, initially used in the medical field since more than 30 years, has been recently developed also for industry to aid in the dimensional/geometrical inspection, material composition characterization, as well as internal assessment of samples. On today's market, many different industrial CT systems are available: from large scanners with linear accelerators that can easily penetrate $300 \mathrm{~mm}$ of steel and handling objects weighting several tons, to portable systems with resolutions better than $1 \mu \mathrm{m}$ for inspection of micro parts [6]. Fundamentally, a CT scanner consists of an X-ray source, a rotary table, 
and an X-ray detector, which converted by a control until computer allow image processing and the analysis of measurement results.

The principle of tomography is straightforward; the $\mathrm{X}$-ray emits photons passing through the object, some of these are absorbed, some scattered and some are transmitted. The ones captured by the detector are projected as radiographic images of the part to be inspected. These images are acquired from different angles as the rotary table spins, then elaborating together all the acquired images, the virtual part is reconstructed.

Nowadays, CT scanning is emerging as a powerful dimensional measuring technique as no competitive measuring system exists for non-destructive inspection of interior surfaces.

Some of its advantages and disadvantages are the following:

Advantages:

- determination of inner and outer geometry;

- possibility to acquire a very high point density in relative short time;

- no material restrictions exist for this technology;

- low inspection time. Approximately for setting the machine it takes $20 \mathrm{~min}$. For calibration $5 \mathrm{~min}$, and for measuring both sides of a $220 \mathrm{~mm}$ length and $85 \mathrm{~mm}$ width work piece area, it takes 35 min approximately. The total inspection service cost is $340 \mathrm{USD} / \mathrm{h}$.

Disadvantages:

- traceability standards under development (VDI/VDE 2630);

- maintenance cost and frequency is elevated compared to tactile technologies (see Tab. 1);

- high equipment cost (see Tab. 2);

- safety concerns with regards to penetrating radiation [11];

- CT's is not a portable technology.

\subsection{Photogrammetry (PG)}

Photogrammetry is a metrology technique in which the shape, size, and position of objects are determined from measurements made in two-dimensional images. Threedimensional coordinates of points of interest are calculated via optical triangulation from two or more images taken from different locations. Photogrammetry is often associated with the production of topographic maps from aerial and satellite images.

From the early 1960s and for nearly two decades thereafter, industrial photogrammetry was used predominately for the calibration of the reflector surfaces of large radio telescopes, parabolic space borne deployable antennas, and for ship building measurements. In the early 1980s, it began to establish itself in aircraft and aerospace manufacturing for the dimensional inspection of tooling fixtures, assemblies, and master gauges [19].

Advantages:

- mobility/portability;

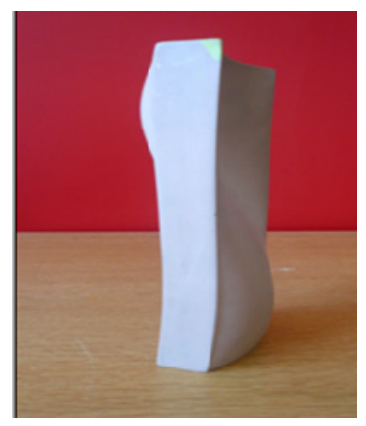

Fig. 2. (Color online) Case study prototype.

- low inspection time. Setting up the machine takes $25 \mathrm{~min}$. The calibration can be done in $10 \mathrm{~min}$ and the measurement of both sides of a $220 \mathrm{~mm}$ length and $85 \mathrm{~mm}$ width work piece area is done in $25 \mathrm{~min}$. The total inspection service cost is $390 \mathrm{USD} / \mathrm{h}$;

- possibility to acquire a very high point density in relative short time;

- accuracies between ranges of 0.01-0.6 mm depending on the size of the work piece [20].

Disadvantages:

- maintenance cost and frequency is elevated compared to tactile technologies (see Tab. 1);

- material restrictions over translucent/reflective materials (preparation required affecting $3-5 \mu \mathrm{m}$ in measurements);

- traceability standards under development (VDI/VDE 2634) [21];

- Reduced size measurements capability.

\section{Technologies comparison}

Commonly the information provided from suppliers is not descriptive of all the complete requirements for visualizing the total cost and trainings required when acquiring measurement equipment. As well, it is relevant to mention the uncertainty of the instrument and data registered in the brochures it is usually obtained using prismatic shapes thus, with the purpose to validate such information on a real sculptured surface, a prototype of a turbine blade meso-scale was manufactured in a material called PROLAB 65, which consists basically of polyurethane the design gridline was a $9 \times 9$ mesh, measuring only the $+X+Y+Z$ surface. The general dimensions of the sample were a length of $220 \mathrm{~mm}$, width: $85 \mathrm{~mm}$, and a height of $75 \mathrm{~mm}$ (peak to valley) (see Fig. 2). This case study permitted to obtain the reproducibility and the uncertainty of the measurements performed on the sample. For this experimentation in the three different technologies were used three repetitions in each of the instruments to calculate the experimental data of the aspects mentioned above as well as some recommendation towards the alignment.

Before discussing the differences in uncertainty and reproducibility from the comparison, it is important to discuss the measurement process. 


\subsection{Measuring procedure}

In order to obtain the traceability of the CMM measurements, 4 repetitions were performed with the ZEISS OMC 850 machine with $M P E_{C M M}=3+\frac{L}{250}[L$ in mm] software Calypso 4.2.08, scale resolution of $0.2 \mu \mathrm{m}$ over a calibrated sphere certificate information in [8].

Because there is not a complete reference artifact matching the entire work piece only one portion of the sample with a curvature resembling the reference sphere will be examined and compared. The curvature of the work piece resembled a $106 \mathrm{~mm}$ diameter sphere.

According to this source; diameter, uncertainty and sphericity of the artifact are as follows:

$$
\begin{aligned}
\text { Dnominal }_{\mathrm{sph}} & =108 \mathrm{~mm} \\
\phi_{\mathrm{sph}} & =(107.943 \pm 0.003) \mathrm{mm}, \\
\text { Sphericity } & =4.5 \mu \mathrm{m} .
\end{aligned}
$$

Regarding the sphere diameter, the characteristics taken into account for its selection are in accordance to standard ISO 15530-3 (2004) [5].

The 4 repetitions performed to the reference were carried out at the upper part of the sphere where 100 points with $0.1 \mathrm{~mm}$ spacing (similar conditions used for the sample) were measured.

Subsequently, 2 days after the sphere measurements, 3 repetitions were performed on the sample considering 81 points over the work piece. These were done repositioning after each measurement in order to have reproducibility and verify consistency of the results. The RPS CAD alignment described in Section 3.1 was done after each measurement.

It is important to mention only the points covered by the curvature of the sphere will be taken into account for the uncertainty calculation since are the only ones with the sphere traceability.

Regarding the uncertainty budget according the ISO/TS 15530-3 "use of calibrated work pieces or standards" the following formula describes the uncertainty calculation:

$$
U=k \sqrt{u_{c}^{2}+u_{p}^{2}+u_{w}^{2}+|b|}
$$

where:

$U_{\text {cal }}$ : uncertainty of the calibrated work piece stated in the calibration certificate;

$u_{p}$ : uncertainty from the measurement procedure in the calibrated work piece;

$u_{w}$ : uncertainty resulting from the material and manufacturing variations;

$|b|$ : systematic error between indicated value of the CMM and value of calibrated work piece;

$k$ : coverage factor $(k=2$ for a coverage probability of 95\%).

The measurements performed in the Tomography equipment were performed in a METROTOM 1500 with Calypso 4.8.10.01 software. The machine setup had an FDD $1500 \mathrm{~mm}$, FOD $900 \mathrm{~mm}$, and voxel size of $241 \mu \mathrm{m}$.
The photogrammetry inspection required the ATOS SO4 machine with software ATOS version 6.2.0-6. The machine setup for the acquisition had a density of $15 \mu \mathrm{m}$ captured with two cameras.

For the CT and photogrammetry measurements it was not required any reference artifact.

Currently the only available standard for uncertainty evaluation for CT is the German VDI/VDE 2630, and for photogrammetry is the VDI/VDE 2634, both being drafts. Another way of calculating the uncertainty in these cases is regarding the CMM measurements as reference since these are much more accurate and have traceability according to the IEC 15530-3 standard. These measurements allow in this way to the CT and photogrammetry measurements to have traceability and calculate the uncertainty of the acquisitions.

Having this premise as consideration, equation (2) judges the agreement between two measurement results calculating deviation $E_{n}$ normalized with respect to the stated uncertainties [7]:

$$
E_{n}=\frac{x_{l a b}-x_{r e f}}{\sqrt{U_{l a b}^{z}-U_{r e f}^{z}}}
$$

$x_{r e f}$ and $x_{l a b}$ : measurement results from two laboratories;

$U_{\text {ref }}$ and $U_{l a b}$ : laboratories uncertainties.

With this method it is possible to decide if it exists agreement between the two measurements, and calculate the uncertainty of the laboratory results.

The agreement calculation is determined according to the absolute values of $E_{n}$. If $E_{n}$ is less than unity, it indicates good agreement, while if the values are equal or larger than 1, it expresses the estimated uncertainties do not reflect real conditions.

Following the $E_{n}$ approach, the average of the $3 \mathrm{CMM}$ repetitions is required as reference for the comparison with 3 CT repetitions relocated after each scan.

The CAD alignment of CT and photogrammetry using the RPS method required the same $X Y Z$ coordinates of the points in the CMM RPS alignment. Nevertheless, we also require considering some accuracy might get lost after stitching the point cloud acquired with CT or photogrammetry with the CMM measurements. If the alignment points used for the CMM inspection were not enough, the accuracy of the measurements might be affected same as the $E_{n}$ value approach.

\subsection{Uncertainty and reproducibility results}

The uncertainties and reproducibilities obtained from the measurements and the calculations using equations (1) and (2) (see Tab. 1) demonstrated the uncertainty gathered in technical specifications is in agreement with the experimental data. For CMM the total uncertainty is $5 \mu \mathrm{m}$, with an MPE of $2.6 \mu \mathrm{m}$ considering the CMM Zeiss OMC 850 according to the technical specifications an equipment of high accuracy. 


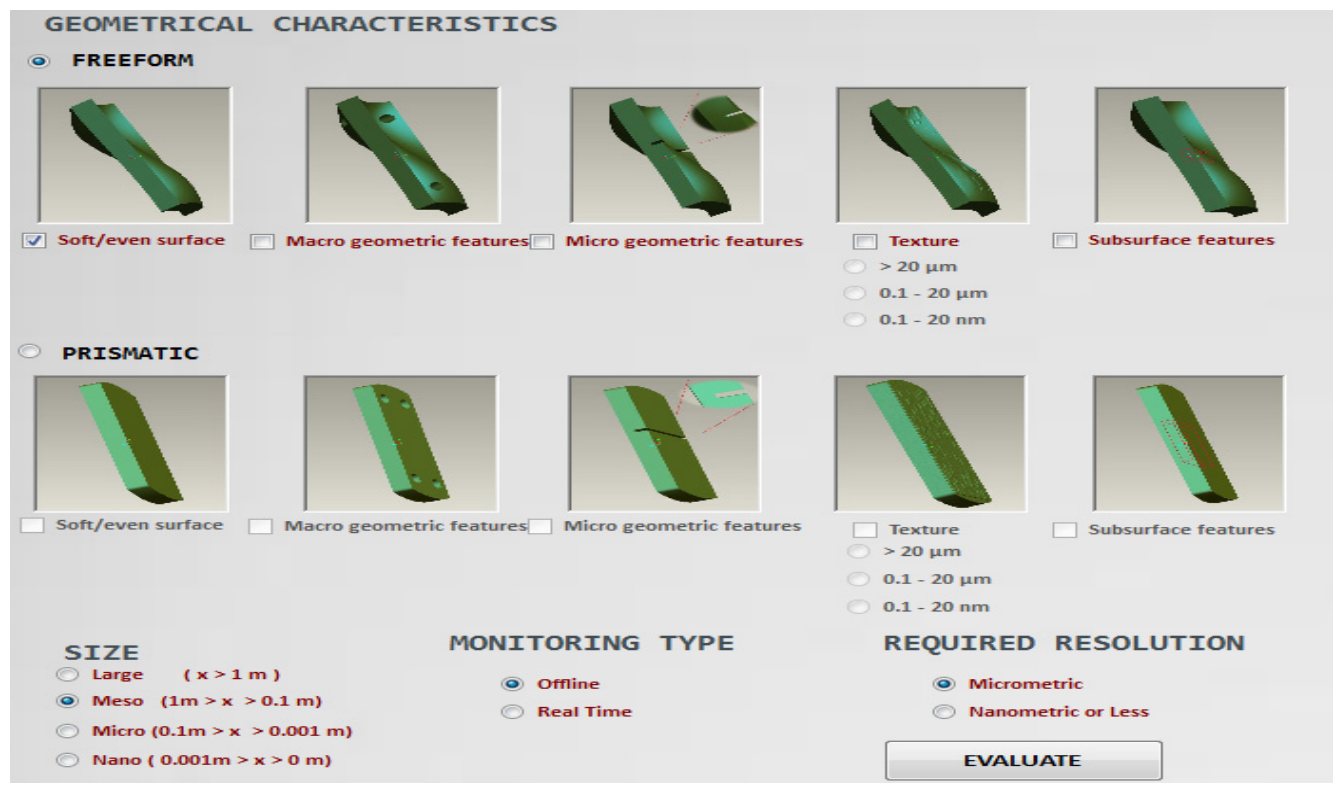

Fig. 3. (Color online) Inspection technology's application.

Uncertainties for CT and photogrammetry of $13 \mu \mathrm{m}$ and an MPE of $11 \mu \mathrm{m}$ are also within the technical specification range between $4-20 \mu \mathrm{m}$.

The reproducibility for the tactile CMM, CT and photogrammetry reported $5 \mu \mathrm{m}, 21 \mu \mathrm{m}$ and $18 \mu \mathrm{m}$ respectively (see Tab. 1) indicating more consistency in the CMM measurements as first choice and photogrammetry as the second.

Again, differences might exist depending on the amount of points used for alignment.

\subsection{Equipment costs and recommendations}

Another important consideration for a proper evaluation of these three metrology technologies is to consider the variation of cost in the equipment depending on the size of the machine. To aid in such matter Table 2 gives a general overview taking the first and second technology selection considering the dimensions of the samples to measure. The table suggests the acquisition of a photogrammetry technology when samples are larger than $1 \mathrm{~m}$. The advantage of photogrammetry over the CMM is the time and easiness for measuring large objects with a relative low MPE and expected low uncertainty.

In same case with large scale components, if there is not much budget for acquiring more equipment, the suggestion can be to hire a CMM inspection service after sampling a certain amount of pieces by faster means like CT or photogrammetry so that training the personnel in the use and standards of the machine, acquisition of equipment, and maintaining the lab in the conditions mentioned for the ISO/IEC 17025 can be avoided costs.

For meso-scale components the recommendation depends more in the expertise of the personnel and the desired accuracy and uncertainty of the results. From one side, it can be recommended to use photogrammetry for the inspection, especially if the work pieces are difficult to handle like freeform and there is not enough expertise of the personnel, or the appropriate reference artifact. Nevertheless, if the components to measure have tight tolerances, or the sample is a geometric feature with planes, the recommendation would be to choose the CMM.

On the other hand, for small parts or biomedical systems, one inspection option would be to acquire a computed tomography apparatus given that the inspection time, the relatively low MPE, and the ability to perform internal and non-destructive analysis of the sample make it a very good option even towards the CMM. This technology is ideal to analyze existence of cracks or defects in the material.

In order to facilitate the evaluation of inspection technologies to industry a C\# application (see Fig. 3) containing the gathered information of the analyzed inspection equipment has been developed with the intention to become a powerful tool for the acquisition of inspection machinery. For other technologies it will be required to perform additional experimentation (future work).

\section{Conclusions}

Measuring free form surfaces is still a task subjected to continuous improvements. When time and accuracy are important factors it is difficult to decide the most appropriate technology to purchase or use. For such reason the objective of this work was to summarize all recommendations, regulations, costs and validate the equipment specifications when a freeform meso-scale sample is to be measured in a CMM, computed tomography, or photogrammetry equipment.

In this work, technical specifications were validated through experimental data (see Tabs. 1 and 2). It was 
explained the steps to select the appropriate technology starting from analyzing the work piece at first. This is important because the inspection can become difficult depending on the material, size, shape and these facts may affect the election of the most suitable equipment for the metrological inspection.

As a second matter to take into account are the proper characteristics of each type of technology such as time of inspection, cost, necessary knowledge to comply with an accurate inspection, and possible choices like hiring a measurement service in case the acquisition of new equipment is not a potential option.

After the advantages and disadvantages have been determined, it is required to analyze the measurement complications which may occur during the measurement process. Some technologies like photogrammetry and computed tomography are easier to handle but with the drawback of having the traceability standards under development.

Managing the uncertainty is a complex task in CT and photogrammetry. However, some approaches like the $E_{n}$ have been already developed to simplify the uncertainty calculations in order to have a convenient method of judging the agreement between two measurement results. With this approach it is possible to estimate the uncertainty of the laboratory results (CT or photogrammetry) having the uncertainty and the average of the standard deviations of the CMM measurements. If the Absolute values of $E_{n}$ are less than unity indicate good agreement while values equal to or larger than 1 express that the estimated uncertainties do not reflect real conditions.

As a future approach and intent to satisfy the strict demands with short times to evaluate inspection technologies, is the presentation of an application subroutine summarizing the information of tables 1 and 2 containing data gathered from the three investigated technologies of this work, particularly in meso-scale. The aim is to continue completing experimental research and gathering useful information so that it can become a decision making tool in high precision manufacturing industry.

Acknowledgements. The authors would like to thank the Mexican Council of Science and Technology (CONACYT) scholarships program.

\section{References}

1. B. Neumann, The Interaction between Geometry and Performance of a Centrifulgal Pump (Mechanical Engineering Publications, London, 1991)

2. Technical Report, RMP 600/OMP 400, Renishaw, http://resources.renishaw.com
3. T. Nishiguchi, Y. Koizumi, Y. Maeda, M. Masuda, K. Nagayama, Development of productivity in aspherical precision machining with in-situ metrology, CIRP Ann. 40, 367-370 (1991)

4. R. Schmitt, D. Doerner, Measurement technology for the machine-integrated determination of form deviations in optical surfaces, CIRP Ann. 55, 559-562 (2006)

5. ISO 15530-3:2004, Geometrical Product Specifications (GPS) - Coordinate measuring machines (CMM): Technique for determining the uncertainty of measurement - Part 3: Use of calibrated workpieces or standards

6. E. Savio, L. De Chiffre, R. Schmitt, Metrology of freeform shaped parts, CIRP Ann. 56, 810-835 (2007)

7. L. De Chiffre, Geometrical Metrology and Machine Testing (Textbook, Polyteknisk Forlag, 2011)

8. E. Barini, G. Tosello, L. De Chiffre, Uncertainty analysis of point/by/point sampling complex surfaces using touch probe CMMs. DOE for complex surfaces verification with CMM, Precis. Eng. 34, 6-21 (2010)

9. J.R. Zeleny, El proceso de medición con CMM, Instituto de Metrología Mitutoyo Mitutoto Mexicana, S.A. de C.V., Technical Report (Spanish), 2005

10. N. Gester, S. Cupypers, P. Bleys, J. Kruth, A performance evaluation test for laster line scanners on CMMs, Opt. Lasers Eng. 47, 336-342 (2009)

11. S. Carmignato, Traceability of coordinate measurements on complex surfaces, Ph.D. thesis, DTU (Technical University of Denmark) and University of Padova, 2005

12. Technical Report, Industrial 3D Measurement Technology, Quality Control and Inspection Utilizing the ATOS 3D Scanner, GOM optical Measuring Techniques

13. Technical Report, Xspect Solutions Wenzel, Wenzel RAD 3025 size 120.30 .25

14. Technical Report, Xspect Solutions Wenzel, Wenzel RSD Plus 3025 size 55.30 .25

15. Technical Report, Cordax 20.33.15/Sheffield Endeavor 2, Coordinate Measuring Machine

16. Technical Report, Smart CMM \& X-Orbit Series/Wenzel, Bridge Coordinate Measuring Machines, Wenzel XO 108 size 10.12 .08

17. Technical Report, METROTOM 1500, http://www. qualitydigest.com/inside/metrology-article

18. Technical Report, METROTOM 800, http://www. machines 4 u. com.au

19. W.T. Estler, K.L. Edmunson, G.N. Peggs, D.H. Parker, Large-scale metrology-an update, CIRP Ann. 51, 587-609 (2002)

20. Technical Report, Industrial 3D Measurement Technology, Quality Control and Inspection Utilizing the ATOS 3D Scanner, GOM optical Measuring Techniques

21. VDI/VDE 2634-2:2002, Optical 3d Measuring Systems Optical Systems Based On Area Scanning 